\title{
The role of values in social innovation transfer
}

What role do values play in knowledge transfer between social enterprises, and what or inhibit the exchange of are the questions behind new of Wheaton College in Massachusetts, USA. Looking a social entrepreneurship through the lens of a partnership to transfer a model of affordable to South America, his work for programme manons consultants, and professionals in different settings worldwide. are the factors which facilitat research by Imran Chowdhury eye-care services from India

mran Chowdhury, Associate Professor of Business \& Management and the inaugural Diana Davis Spencer Chair of Social Entrepreneurship at Wheaton conducts research at the intersection of business and society His work covers topics such as social entrepreneurship corporate social responsibility, philanthropy, and community-focused organisations.

Dr Chowdhury is particularly interested in organisations that pursue joint social and economic goals and use business strategies and methods to achieve socia objectives. Distinct from corporates which use profits to pursue philanthropic goals, and non-profits which fund services by developing revenue streams, these 'models of social entre

Dr Chowdhury's latest work looks at what happens when hybrid organisations

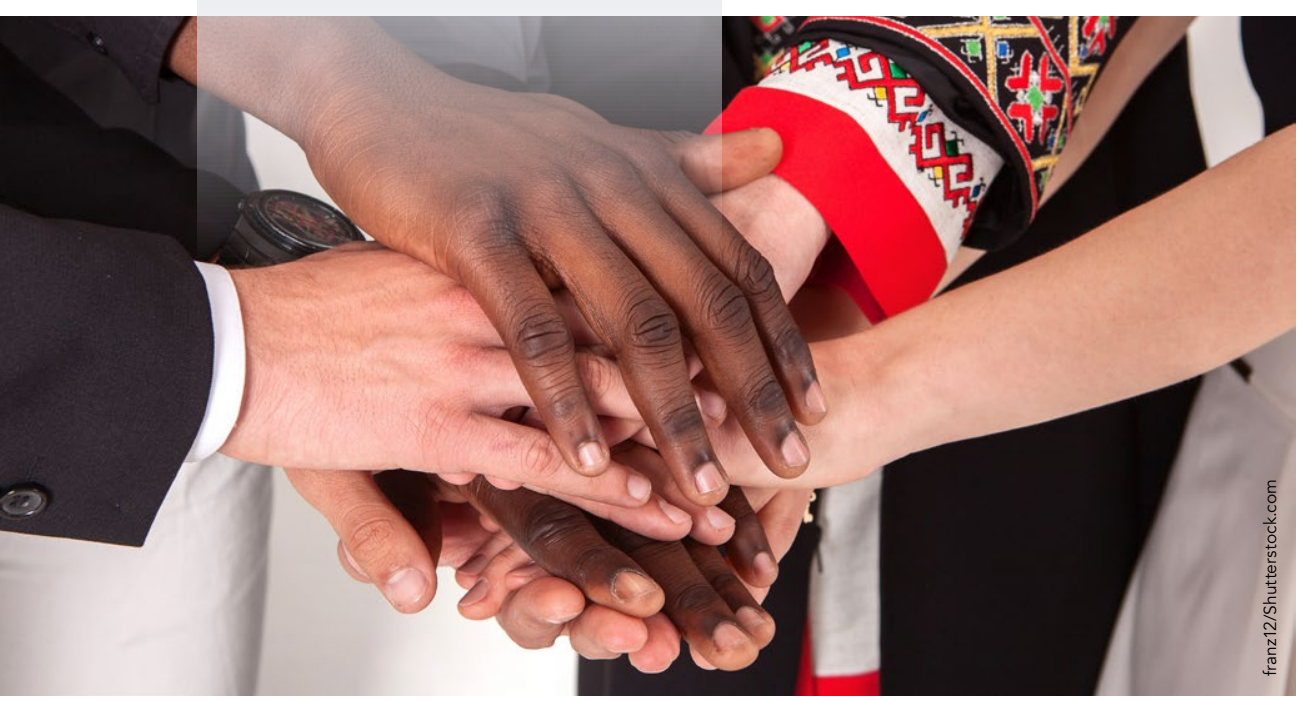

seek to transfer their models of social innovation to partners with different for between organiation pact varies The research is based on a lngitudinal, qualitative field study of three social enterprises that formed a partnership to scale-up social innovation and adap a model of affordable eye-care senvices developed in India to a clinic in Paraquay South America.

Dr Chowdhury's focus is on how organisations manage relationship and resolve conflicting demands emanating from their internal and externa environments. In addition, his research examines the factors that influence knowledge transfer between partners in different sethings, particularly the role tha

\section{FIELD STUDY}

Located in the city of Madurai in southern the 45 yravind Eye Hospital has more eye-care senvices to poor people, with the aim of eliminating needless blindness. In 2017/2018, the hospital recorded more than four million outpatient visits and performed nearly half a million surgeries Half of these were delivered at no cost to the patient.

ounded in 1992, Fundación Visión is based in Paraguay's capital Asuncion and leads blindness prevention in the country. It is the only institution that provides opthalmological outreach services in ural areas. Eye-care procedures can the cost, Fundación Visión linked up

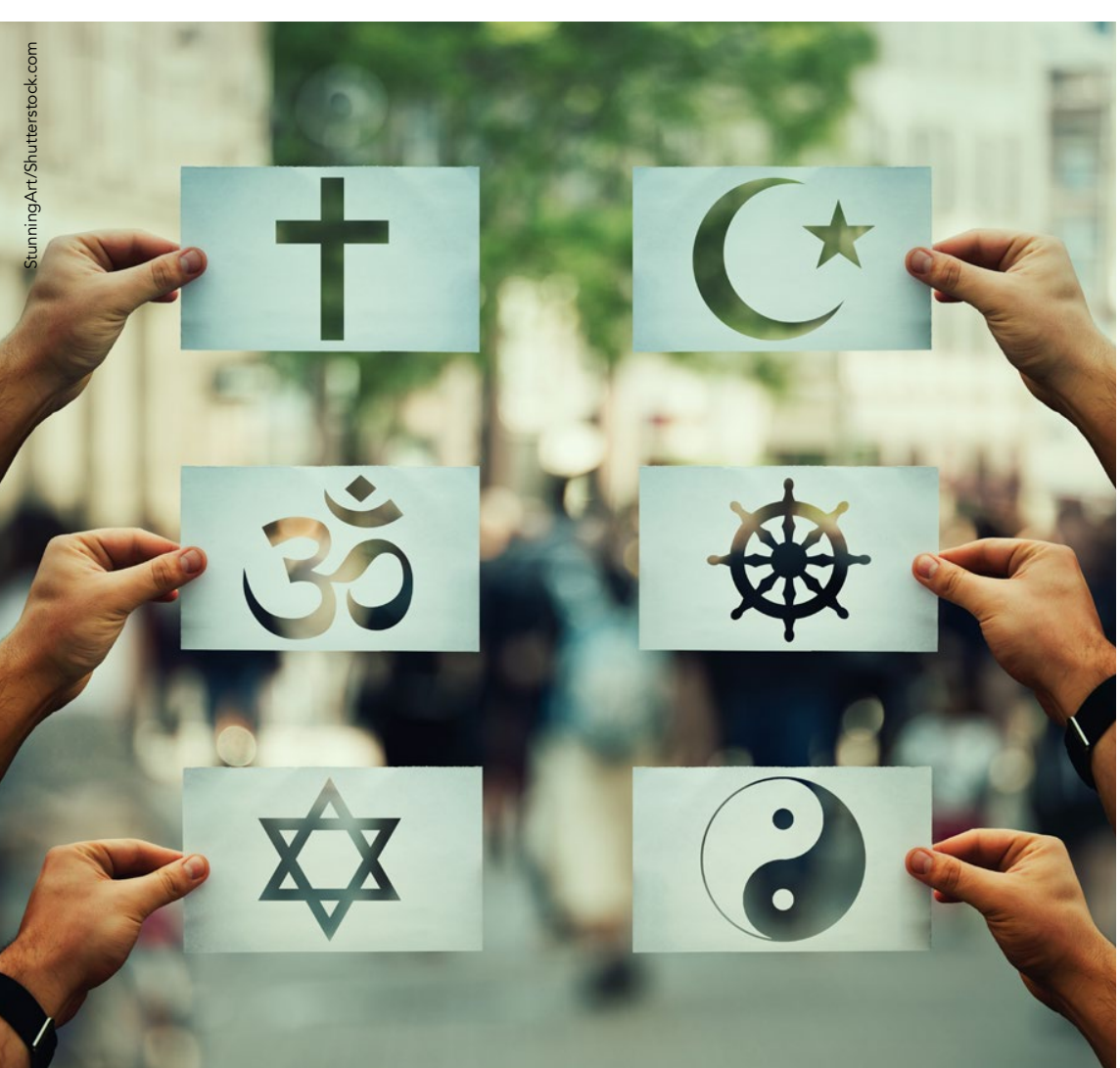

Pr Chowdhury's study sheds light on faith and entrepreneurship and the importance of

with Fundación Paraguaya, a leading microfinance provider with a network of local offices and contacts in remote areas of the country.

Aravind, Fundación Visión and Fundación Paraguaya have formed a partners to transfer expertise from India to Paraguay. Although both countries are mepung economies, Arawnd is based in pisín and Fund sectíng and Fundación
CHRONOLOGIES AND LOGICS Analysis of the data gathered allowed $D$ Chowchury to identify key moments in te development of the partnership and code them according to how, as hybrid organisations, partners managed and aligned their social and economic logics. The results showed the existence of multiple competing logics which complexity - The most variation betwe
Despite the partners' different religious Fungrounds, the fact that Aravind and spiritual logic and shared an underlying commitment to a 'higher power' was a mportant point of unity and common collaboration between the two clinical systems and mitigate clashes when there was a mismatch of economic logics.

contrast, decision-making in Fundación Paraguaya was informed by a socia welfare logic which focused on the provision of products and senvices to thress local social needs, but privileged tose who 'deserved support. In addition, Fundación Paraguaya and Fundación organisations' social logics.

It was vitally important that common ground was found between Fundació Paraguaya and Fundación Visión,

because the microfinance organisation's country-wide local network provided the patients for its outreach eye-care services.

\section{THEORETICAL BACKGROUND} Dr Chowdhury's analysis of the study data suggests that how organisations respond to and manage conflicting demands can be a function of their ethica backgrounds and cultures. In this way it builds on the work of the American social psychologist Jonathan Haidt, who studies the psychology of morally. Dre Chowdhury examining how vaning social motivato with dispersed
populations in
remote settings, $\quad$ Negotiating in good faith with partners $\begin{aligned} & \text { (emerging from varied } \\ & \text { social logics) can } \\ & \text { manifest as tensions or }\end{aligned}$ where the cost of may result in positive outcomes that conflicts in partnerships, builds on Haidt's notions high. Both clinical both parties can live with. $\begin{array}{ll}\text { based organisations: Fundación Visión is a partner organisations was at the level } \\ \text { Christian organisation and Aravind's work } & \text { of social logics, which Dr Chowdhury }\end{array}$ further identified as either spiritual or social welfare logics. He explains Whereas the social welfare logic obtains legitimacy by making products and delivering services to address local social needs, the spiritual logic obtain legitimacy by linking the provision of social services and goods to an association with deities and faith as its as they emerge in practice.

In addition, the findings demonstrate that in practice, the alignment of the partners' organisational logics and values facilitated the way in which they were able to transfer knowledge about social innovation from a densely populated urban setting in nala to dispersed, rural populations in Paraguay. The alignment of values help 


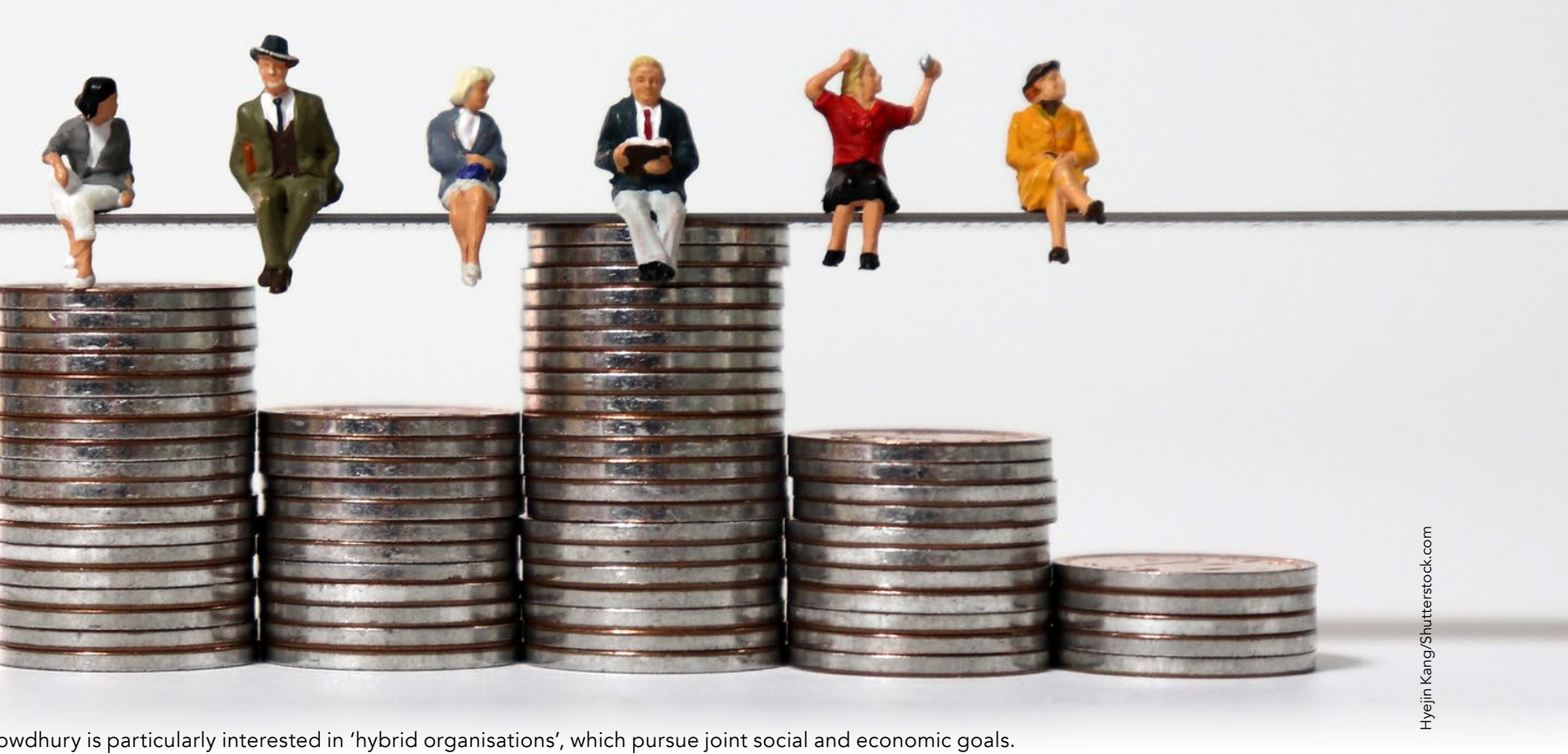

them to work together to find practical solutions to problems which arose. As Dr Chowchury explains: 'Negotiating in good faith with parners may result in positive outcomes that both parties can live with."

Dr Chowdhury's research also helps to advance curent theory on social of 'bricolage'. Made famous by the French anthropologist Claude LéviStrauss in the 1960 s, the 'do-it-yourself' approach to development and problemsolving is to fashion solutions from what is at hand, rather than what may be recommended as ideal.

Dr Chowdhury comments: 'Evidence from the case study suggests that institutional bricolage - the cratting of improvised solutions in resource-constrained setting - can serve as a potent force in driving innovation transfer and the process of re-combining avallable resources may values between partner social entep values between
are combined.'

(a)

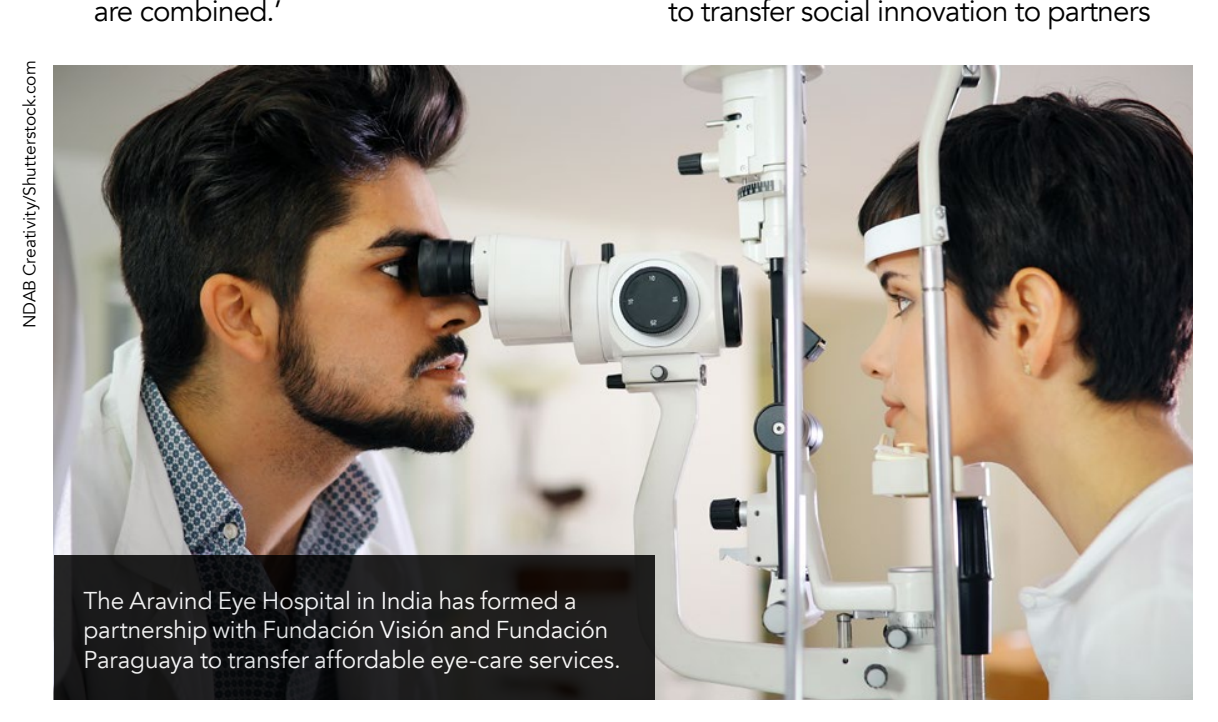

It reveals the important role that
CONCLUSION in distant settings, despite the barriers Dr Chowdhury's study helps us better understand how organisations, particularly hybrid organisations such as social enterprises, balance social
and commercial imperatives to scaleup entrepreneurial innovations. It influence inter-organisational processes and how different social logics can co-exist in partnerships between posed by geography, language, and culture. It further defines the concept of 'social' in the practice of social enterprises who have either a spiritual or social light on faith and entrepreneurship and the importance of organisational belief.

The study has interesting implications in the wake of the global pandemic.

Values alignment helps entrepreneurs to transfer social innovation to partners in distant settings, despite the barriers posed by geography, language, and culture. organisations with different motivations for creating social impact. values alignment plays in international to transfer social innovation to paneus

$-$
Dr Chowdhury's research illustrates the importance of partners modifying practice to fit the context in which they operate, particularly with regard to affected world those constrints could well apply to the urban areas which have been hardest hit by the pandemic. In addition, the pandemic has shown how the universal acceptance of maskSouth Korea - an alignment of values between individuals and the state helped to inhibit the spread of infection at least during the early stages of the COVID-19 outbreak.

Dr Chowdhury comments: 'Focusing on values alignment may therefore be a means to overcome some of the and also help to rebuild trust in public health institutions and other organissat wearing in countries such as Taiwan and andance to measures such as vaccines

\section{Behind the Research} Dr Imran G. Chowdhury

E: chowdhury imran@wheatoncollege.edu T: +15082863915 W: wheatoncollege.edu/academics/

\section{Research Objectives}

Dr Chowdhury examines how common values may help entrepreneurs to transfer social innovations to partners in distant settings.

\section{Detail}

Address

Social Entrepreneurship \& Innovation

26. East Main Street

Norton MA 02766

USA

Bio

Imran Chowdhury, PhD, is the Diana Davis Spencer Chair of Social Entrepreneurship and Associate Professor of Business \& Management at Wheaton College (MA) and Visiting Professor at the Free University of Berlin's International Summer and Winter University. He teaches and conducts research at the intersection of business and society, encompassing domains such as social entrepreneurship corporate social responsibility, philanthropy, and

\section{1 wheaton \\ college}

massachusetts

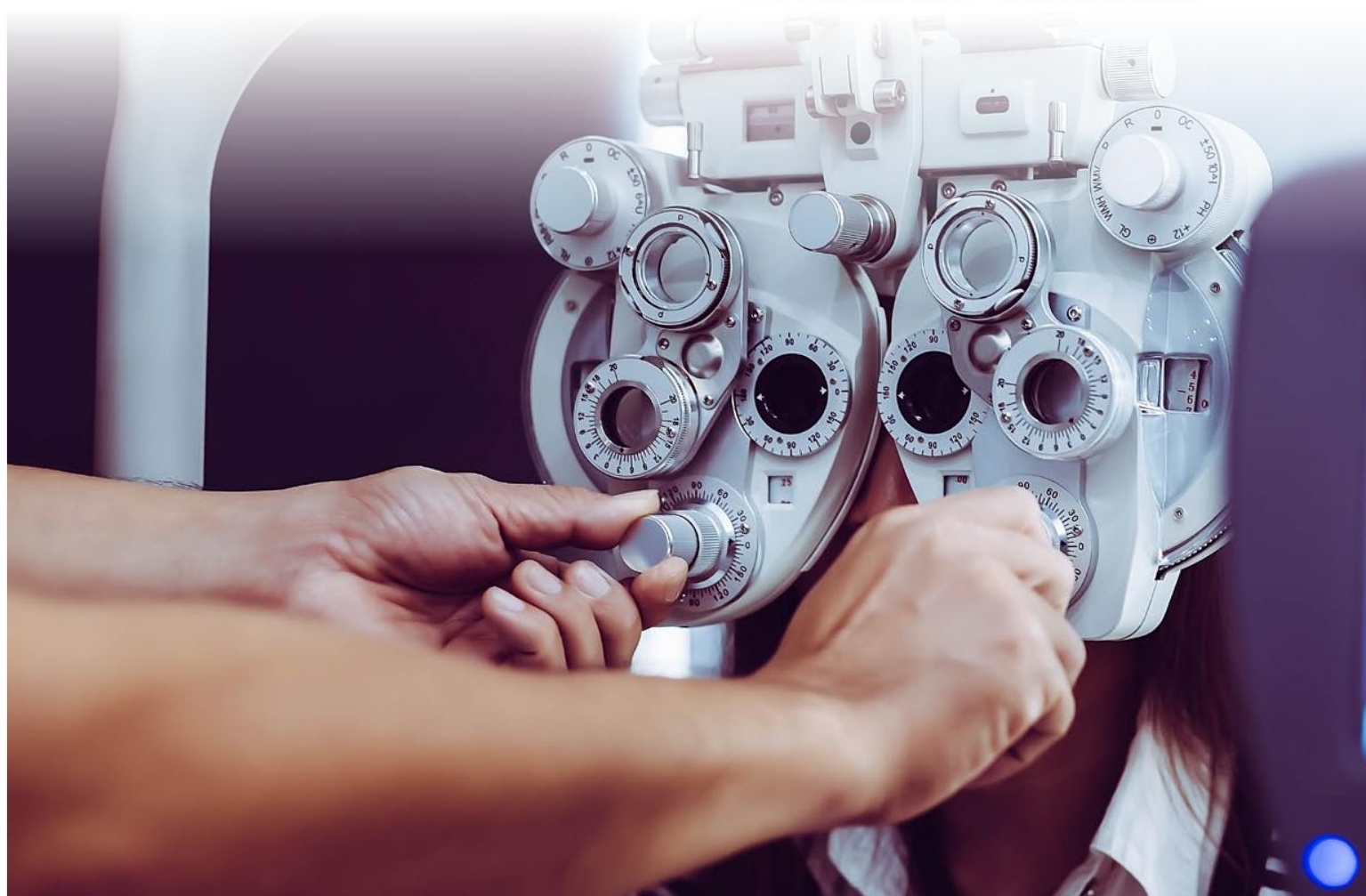

References

Chowdhury, I. (2020). Bridging the rural-urban divide in social Goviton transter. the role of values. Agricuture and Human Values, 37, 1261-1279,
s10406-020-10132-7

\section{Personal Response}

The study highlights the importance of values and What was the most interesting example of these that emerged within your research?

II What stood out for me was how important values alignment was to fashioning solutions which facilitated two focal organisations were in alignment at the The values, both were hospitals guided by spiritual/ religious principles at their core. This speaks to a larger issue in the way we consider social enterprises: while it is easy to group
them under one umbrella, it is important to note that how such organisations seek to create social impact is often as impact in the first place.

I

